\title{
PIOMETRA ABERTA EM UMA CADELA DE 10 MESES
}

\author{
Open Pyometra in a 10 month old Bitch
}

\author{
Ricardo Felice Fan Chen \\ Médico Veterinário, Curitiba - PR. e-mail: chen.ricardo86@gmail.com \\ Patrícia Mara Dainesi Addeo \\ Médica Veterinária, Curitiba - PR. e-mail: vetsan@vetsan.com.br \\ Adolfo Yoshiaki Sasaki \\ Médico Veterinário, Curitiba - PR. e-mail: vetsan@vetsan.com.br
}

\section{Resumo}

A piometra é uma infecção com grande acúmulo de pus no lúmen uterino, que ocorre mais comumente na fase de diestro do ciclo estral da cadela, podendo apresentar-se de duas formas: com secreção vulvar e cérvix aberta ou sem secreção vulvar e com cérvix fechada. A piometra resulta de uma infecção bacteriana no endométrio que sofreu hiperplasia cística devido a uma prolongada estimulação hormonal. O presente relato de caso tem por objetivo alertar o clínico de pequenos animais para a ocorrência de piometra aberta em uma cadela de 10 meses, apresentação esta incomum e não citada na literatura usual.

Palavras-chave: Piometra; Diestro; Cadela.

\begin{abstract}
Pyometra is an infectious disease with large accumulation of pus in the uterine cavity. It usually happens at the bitch diestrus phase of the estrus cycle occurring either with vulva flow and open cervix or without vulva flow and closed cevix. Pyonwtra is a consequence of a bacterial infection of the endometrium that suffered cystic hyperplasia due to a lengthened hormonal stimulation. The main aim of the present report case is to alert the small animals clinicians for the occurrence of an open pyometra in a 10-month old bitch, an uncommon event not cited at the pertinent literature.
\end{abstract}

Keywords: Pyometra; Diestrus; Bitch. 


\section{INTRODUÇÃO}

A piometra é uma infecção supurativa do útero, aguda ou crônica, com grande acúmulo de pus na cavidade uterina. Essa patologia resulta de uma infecção bacteriana no endométrio que sofreu hiperplasia cística em decorrência de uma prolongada estimulação hormonal (COUTO; NELSON, 1998; FERREIRA; LOPES, 2002).

Esta infecção é mediada por hormônios e pode ocorrer em qualquer estágio do ciclo estral, sendo mais freqüentemente observada na fase de diestro (BLENDINGER; BOSTEDT; HOFFMANN, 1997; COUTO; NELSON, 1998; FELDMAN; NELSON, 1996). Aparentemente não há predisposição racial para esta patologia (SEVELIUS; TIDHOLM; THORENTOLLING, 1990; WHEATON et al., 1989). O desenvolvimento da piometra é precedido pela hiperplasia cística endometrial, que é uma resposta exagerada e anormal do endométrio à estimulação da progesterona crônica e repetidamente, levando ao acúmulo de fluído no lúmen uterino e glândulas endometriais (FELDMAN; NELSON, 1996; GANDOTRA et al., 1994; JOHNSON, 1995; PRESTES et al., 1991).

Normalmente, a piometra afeta animais de meia-idade ou idosos, mas animais jovens também podem apresentar essa patologia, em decorrência a tratamentos hormonais (JOHNSON, 1995; MARTINS et al., 2002; SEVELIUS; TIDHOLM; THORENTOLLING, 1990; WHEATON et al., 1989). A piometra possui duas classificações. A primeira consiste em dividir as fêmeas acometidas em jovens e idosas. A piometra que ocorre em fêmeas jovens (com menos de 6 anos) está muito relacionada à terapia de estrógeno e progesterona exógenos. A piometra que ocorre em fêmeas idosas (com mais de 7 anos) decorre da longa e repetida estimulação pela progesterona na fase lútea, com maior freqüência em fêmeas nulíparas (MARTINS et al., 2002).

A segunda classificação é feita conforme a apresentação da piometra. A piometra aberta caracteriza-se pela secreção vaginal e cérvix aberta. A piometra fechada se caracteriza pela distensão abdominal e cérvix fechada (COUTO; NELSON, 1998; GILBERT; NOTHLING; OETTLE, 1989).

Durante o estro, a progesterona leva à proliferação endometrial, secreção glandular e suprime a atividade do miométrio, possibilitando o acúmulo de secreções uterinas glandulares que promovem um ambiente propício para a proliferação bacteriana, que também é favorecida pela inibição da resposta leucocitária à infecção no útero (FELDMAN; NELSON, 1996; GILBERT, 1992; JOHNSON, 1995).

O uso de progestágenos ou estrógenos para prevenção da prenhez é contra-indicado por aumentar a incidência de piometra, já que o estrógeno exógeno aumenta o número de receptores de progesterona no útero (COUTO; NELSON, 1998; FELDMAN; NELSON, 1996; JOHNSON, 1995; MARTINS et al., 2002; PRESTES et al., 1991). Bactérias originárias da vagina podem colonizar o útero com hiperplasia cística endometrial, levando ao desenvolvimento da piometra, sendo Escherichia coli a bactéria mais freqüentemente isolada (COUTO, NELSON, 1998; JOHNSON, 1995; WEISS et al., 2004).

São observados letargia, depressão, inapetência/anorexia, poliúria, polidipsia, diarréia e vômito (ALVARENGA et al., 1995; COUTO; NELSON, 1998; GILBERT, 1992; MEMON; MICKELSEN, 1993; FELDMAN; NELSON, 1996). Na piometra aberta ocorre a secreção vaginal, que varia de sanguinolenta a mucopurulenta (PRESTES et al., 1991). A temperatura retal pode estar normal ou aumentada em decorrência da infecção uterina, infecção bacteriana secundária, septicemia ou toxemia (FELDMAN; NELSON, 1996; JOHNSON, 1995). Deve-se observar o aumento de volume uterino, mas as palpações abdominais devem ser realizadas com cautela, pois existe risco de ruptura uterina (FELDMAN; NELSON, 1996; GILBERT, 1992).

A suspeita de ocorrência de piometra deve ser relevante em cadelas não-castradas, de meiaidade e que têm histórico de uso de anticoncepcional para prevenção da prenhez. Esses animais devem apresentar os sinais clínicos compatíveis com piometra durante ou após o estro. Observa-se o aumento de volume uterino pela palpação cuidadosa e a confirmação deve ocorrer por meio da radiografia ou ultrasonografia (FELDMAN; NELSON, 1996; GILBERT, 1992). 
O diagnóstico diferencial deve ser realizado com vaginites, que podem ocorrer em qualquer fase do ciclo estral e acometem animais de diversas idades; abortamentos; piometra de coto, que ocorre em cadelas que foram castradas, mas em que permaneceram resquícios dos ovários e segmentos do corpo do útero; massas vaginais e gestação (GILBERT, 1992; PRESTES et al., 1991).

O hemograma é um exame muito significativo, podendo indicar anemia normocítica normocrômica não regenerativa de grau leve a moderado, sendo que isso ocorre devido a um efeito supressor das toxinas bacterianas na medula óssea e também devido à perda de hemácias que migram para o local da infecção por diapedese (COUTO; NELSON, 1998; FELDMAN; NELSON, 1996). O volume globular pode estar aumentado devido à desidratação (JOHNSON, 1995). O leucograma, em alguns casos de piometra aberta, pode apresentar-se normal, enquanto que em casos de piometra fechada esse exame pode estar alterado, apresentando uma leucocitose por neutrofilia com desvio à esquerda e neutrófilos tóxicos (JOHNSON, 1995).

Com relação à urinálise, é importante ressaltar o cuidado que se deve ter com a colheita da urina, principalmente nos casos de piometra aberta, já que pode ocorrer contaminação. Quando for realizada a cistocentese, deve-se cuidar para não puncionar o útero, podendo desencadear uma futura peritonite (JOHNSON, 1995). A proteinúria sem piúria e a hematúria podem ser vistas na piometra, sendo que isso ocorre devido à glomerulonefrite por deposição de imunocomplexos (FELDMAN; NELSON, 1996).

Pelo exame bioquímico, observa-se hiperproteinemia devido à hiperglobulinemia ou devido à desidratação. A uréia e a creatinina podem estar aumentadas, indicando o comprometimento renal, pela deposição dos imunocomplexos em glomérulos, devido a grandes quantidades de endotoxinas da infecção pela E. coli ou resultante da desidratação ou choque séptico, o que leva à azotemia renal, devido a menor perfusão dos glomérulos. $\mathrm{O}$ animal pode apresentar acidose metabólica, em decorrência de alterações no equilíbrio ácido básico. As enzimas hepáticas, fosfatase alcalina e aspartato amino transferase podem estar alteradas devido à lesão em hepatócitos pela endotoxemia ou diminuição da circulação no fígado pelo quadro de desidratação (FELDMAN; NELSON, 1996; HARVEY, 1998).

As cadelas com suspeita de piometra devem ser submetidas ao exame de raio $\mathrm{X}$ abdominal para confirmação do diagnóstico, contudo esse teste não diferencia um aumento de volume uterino devido à piometra ou devido a uma gestação inicial, antes da calcificação fetal (FELDMAN; NELSON, 1996; HARVEY, 1998).

O diagnóstico de escolha é o ultra-som, pois com ele pode-se avaliar o tamanho e a espessura do útero e muitas vezes também é possível diagnosticar o tipo de secreção acumulada no lúmen uterino. O ultra-som permite diferenciar um aumento de volume uterino decorrente de uma gestação em fase inicial, onde se pode identificar estruturas fetais moles e batimentos cardíacos de uma piometra. Ao ultrasom, a piometra aparece como uma estrutura tubular com fluído anecóico ou hipoecóico (FELDMAN; NELSON, 1996; HARVEY, 1998).

O tratamento deve ser imediato e agressivo, já que a septicemia e/ou a endotoxemia podem se desenvolver em qualquer momento, se já não estiverem presentes (JOHNSON, 1995). Para tanto, é indicada a fluidoterapia intravenosa para melhorar a função renal, para manter a perfusão tecidual correta e para correção de déficits eletrolíticos existentes (GILBERT, 1992; JOHNSON, 1995). Também deve ser administrado um antibiótico de amplo espectro de ação até que sejam conhecidos os resultados dos testes de susceptibilidade aos antibióticos (GILBERT, 1992; JOHNSON, 1995). É sabido que a OSH (ovariosalpingohisterectomia) é o tratamento de eleição para a piometra, mas, caso o proprietário tenha interesses reprodutivos, evidentemente essa não poderá ser realizada (FELDMAN; NELSON, 1996; GILBERT, 1992; JOHNSON, 1995).

O tratamento medicamentoso é justificável caso o proprietário tenha interesse reprodutivo da cadela acometida (FELDMAN; NELSON, 1996; GILBERT,1992;JOHNSON, 1995). Após essa modalidade de tratamento da piometra, devem-se cobrir as cadelas no primeiro estro e, assim, continuar por todos os estros até obtenção do número de crias desejado ou até que ocorra recorrência da piometra, onde então a OSH (ovariosalpingohisterectomia) deverá ser considerada (GILBERT, 1992; JOHNSON, 1995). 


\section{MATERIAIS E MÉTODOS}

Para o diagnóstico da piometra, foi colhida amostra de sangue para a realização dos exames de hemograma, bioquímico e leucograma. Também foi utilizada amostra da urina para a realização da urinálise. Foi solicitado um ultra-som para a confirmação do diagnóstico da piometra aberta. Frente ao diagnóstico de piometra aberta, foi recomendada ovariosalpingohisterectomia como medida terapêutica.

Uma cadela, raça lhasa apso, de 10 meses de idade, foi atendida na VetsaN® - Centro Médico Veterinário, Curitiba - Paraná, apresentando secreção vaginal purulenta abundante um dia antes. A cadela apresentou o primeiro cio dois meses antes do atendimento, não tendo uso de medicações anticoncepcionais e não fora cruzada; apresentava êmese, anorexia e polidipsia há um dia.

Ao exame físico, foi detectada secreção vaginal de aspecto purulento, aumento dos linfonodos inguinais, aumento de volume abdominal e intensa dor à palpação abdominal. Em vista da anamnese e do exame físico, suspeitou-se de piometra aberta e foi solicitado exame ultra-sonográfico, que detectou aumento uterino com parede uterina espessada e mucosa irregular, com presença de cistos e secreção uterina de aspecto hipoecogênico.

Frente ao diagnóstico de piometra aberta, foi recomendada ovariosalpingohisterectomia como medida terapêutica. Iniciou-se o tratamento para controle da êmese com metoclopramida $0,5 \mathrm{mg} /$ $\mathrm{kg}$, via subcutânea a cada 12 horas, e cloridrato de ranitidina $2 \mathrm{mg} / \mathrm{kg}$ via subcutânea, a cada 12 horas, com intuito de proteção do trato gastrintestinal.

A intervenção cirúrgica foi realizada com sucesso, observando-se aumento de volume uterino intenso (FIGURA 1), espessamento e distensão da parede uterina e presença de secreção purulenta no lúmen uterino.

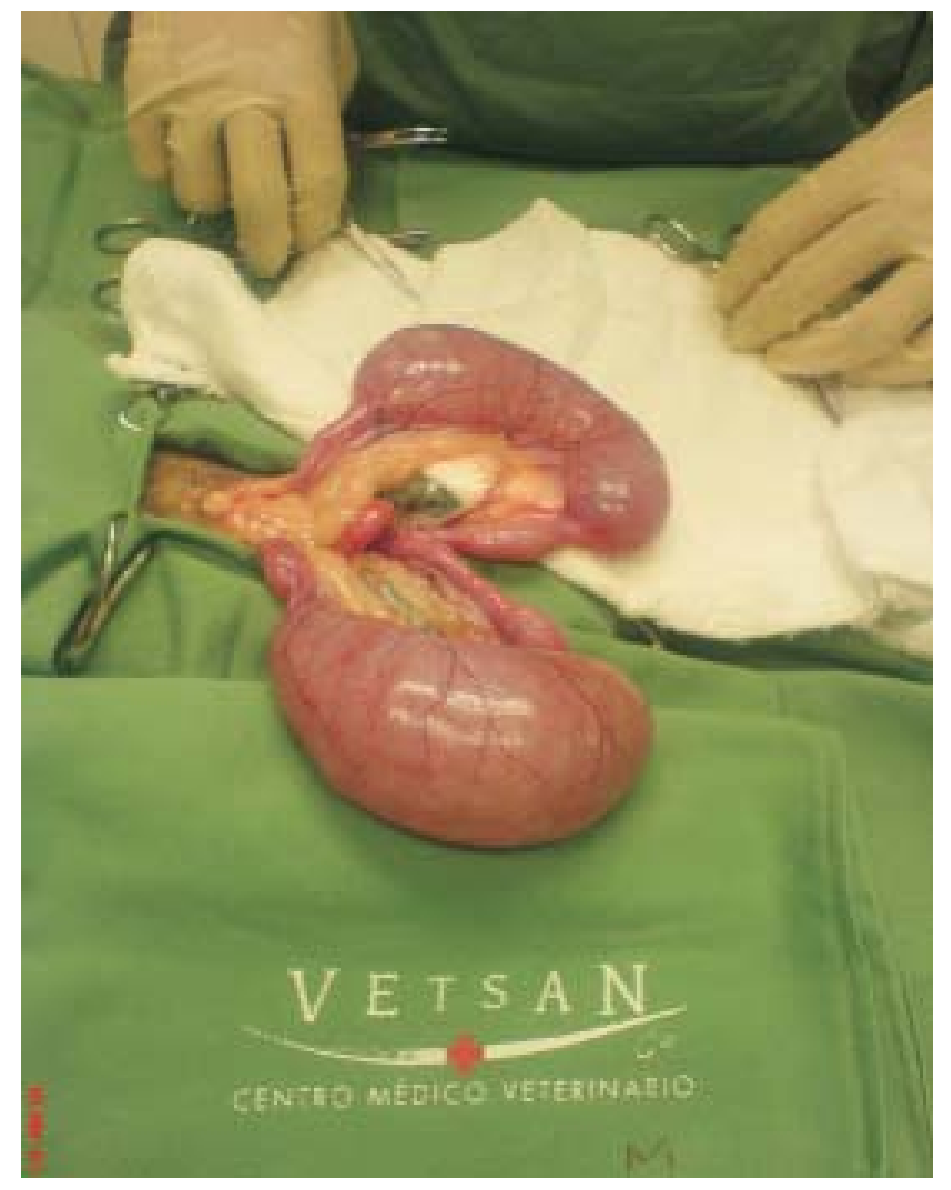

FIGURA 1 - Aumento da capacidade uterina

Figure 1 - Enlargement of the uterine capacity 
Instituiu-se o tratamento pós-cirúrgico com uso de antiinflamatório não-esteroidal (meloxicam $0,2 \mathrm{mg} / \mathrm{kg}$ via intramuscular em dose única e em seguida $0,1 \mathrm{mg} / \mathrm{kg}$ via oral a cada 24 horas, durante 3 dias) e antibioticoterapia de amplo espectro de ação (enrofloxacina $5 \mathrm{mg} / \mathrm{kg}$ via oral a cada 24 horas durante 10 dias) precedida de proteção do trato gastrintestinal (omeprazol 0,7 mg/kg via oral a cada 24 horas, durante 10 dias).

Em retorno realizado após 3, 5 e 10 dias da intervenção cirúrgica, a paciente apresentava-se ativa e saudável, sem queixa de êmese ou demais alterações.

\section{CONCLUSÕES}

Neste relato de caso, verificou-se que a paciente em questão é jovem, porém nunca submetida à terapia contraceptiva. Ao contrário do que a literatura relata, o presente caso alerta para a ocorrência de piometra em animal jovem. Isso deve levar o clínico de pequenos animais a ficar mais atento e suspeitar da ocorrência de piometra mesmo em cadelas nesta situação, ou seja, jovem e sem histórico de uso de contraceptivo. Desta forma, com a suspeita clínica e posterior confirmação diagnóstica, o clínico poderá mais rapidamente intervir cirurgicamente, promovendo o tratamento e a melhora da paciente. A questão mais intrigante é a da ocorrência tão precoce da piometra. Cabe aos pesquisadores desvendar outros fatores correlacionados com o desenvolvimento desta infecção uterina.

\section{REFERÊNCIAS}

ALVARENGA, F. C. L. et al. Ultrasonic diagnosis of pyometra in bitches. Brazilian Journal of Veterinary Research and Animal Science, São Paulo, v. 32, n. 2, p. 105-108, 1995.

BLENDINGER, K.; BOSTEDT, H.; HOFFMANN, B. Hormonal state and effects of the use of an antiprogestin in bitches with pyometra. Journal of Reproduction and Fertility, Birmingham, p. 317 325, 1997. Suplemento 51.

COUTO, R. W.; NELSON, C. G. Distúrbios da vagina e do útero. In: Medicina interna de pequenos animais. Rio de Janeiro: Guanabara Koogan, 1998, p. 681-684.

FELDMAN, E. C.; NELSON, R. W. Canine and feline endocrinology and reproduction. 2. ed. Philadelphia: WB Saunders Company, 1996.

FERREIRA, C. R.; LOPES, M. D. Complexo hiperplasia cística endometrial/piometra em cadelas: revisão. Revista Clínica Veterinária, São Paulo, v. 27, p. 36-44, jul./ago. 2000.

GANDOTRA, V. K. et al. Haematological and bacteriological studies in canine pyometra. Indian Veterinary Journal, Nandam Chennai, v. 17, n. 8, p. 816-818, 1994.

GILBERT, R. O Diagnosis and treatment of pyometra in bitches and queens. The Compendium on Continuing Education for the Practicing Veterinarian, Lawrenceville, v. 14, n. 6, p. 777 -783, 1992.

GILBERT, R. O; NOTHLING, J. O.; OETTLE, E. E. A retrospective study of 40 cases of canine pyometra - metritis treated with prostaglandin $\mathrm{F}_{2}$ - alpha and broad - spectrum antibacterial drugs. J. Reprod. Fert Supp1, n. 39, p. 225-229, 1989.

HARVEY, M. Condions of the non - pregnant female. In: SIMPSON, G.; ENGLAND, G.; HAVEY, M. Manual of small animal reproduction and neonatology. Gloucester: British Small Animal Veterinary Association, 1998. p. 35-51.

JOHNSON, A. C. Cystic endometrial hyperplasia, pyometra and infertility. In: ETTINGER, S. J.; FELDMAN, E. C. Textbook of Veterinary Internal Medicine. $4^{\text {th }}$ ed. Philadelphia: W, B. Saunders Company, 1995. v. 2, p. 1636-1641. 
LOPES, M. D. et al. Aspectos microbiológicos da secreção uterina e da urina de animais com piometra canina. Revista Brasileira de Reprodução Animal, Belo Horizonte, v. 26, p. 123 - 124, 2002.

MARTINS, L. R. et al. Correlação entre a ocorrência de piometra em cadelas nulíparas e multíparas submetidas ou não ao tratamento com anticoncepcionais. In: MOSTRA DE INICIAÇÃO CIENTÍFICA, 6., 2002, Botucatu. Anais... Botucatu: UNESP, 2002.

MEMON, M. A; MICKELSEN, W. D. Diagnosis and treatment of closed - cervix pyometra in the bitch. Journal of the American Veterinary Medical Association, Savoy, v. 203, n. 4, p. 509-512, 1993.

PRESTES, N. C. et al. A Piometra canina: aspectos clínicos, laboratoriais e radiológicos. Semina, Londrina, v. 12 , n. 1, p. 53-56, 1991.

SEVELIUS, E.; TIDHOLM, A; THORENTOLLING, K. Pyometra in the dog. Journal of the American Animal Hospital Association, Denver, v. 26, n. 1, p. 33-38, 1990.

WEISS, R. R. et al. Histopathological, hormonal, bacterial evaluation in bitch pyometra. Archives of Veterinary Science, Curitiba, v. 9, n. 2, p. 81-87, 2004.

WHEATON, L. G. et al. Results and complications of surgical treatment of pyometra: a review of 80 cases. Journal of the American Animal Hospital Association, Savoy, v. 25, n. 5, p. 563-568, 1989.

Recebido em: 18/12/2006

Received in: $12 / 18 / 2006$

Aprovado em: 30/03/2007

Approved in: 03/30/2007 